\title{
PRINCÍPIO FUNDAMENTAL DA SUSTENTABILIDADE E AS INCONSTITUCIONAIS ISENÇÓES TRIBUTÁRIAS A AGROTÓXICOS
}

FUNDAMENTAL PRINCIPLE OF SUSTAINABILITY AND THE UNCONSTITUTIONAL TAX

EXEMPTIONS TO PESTICIDES

Thaís Aurélia Garcia

Defensora Pública Federal

Integrante do Grupo de Trabalho de Garantia à Segurança Alimentar e Nutricional da DPU e do Fórum de Combate aos Impactos dos Agrotóxicos e Transgênicos do Distrito Federal. Mestre em Direito Processual e Cidadania - Universidade Paranaense thais.garcia@dpu.def.br

\section{RESUMO}

Este artigo visa a identificar as desoneraçóes tributárias a agrotóxicos no Brasil e a analisar a (in)constitucionalidade dessas renúncias fiscais, tendo em conta os direitos fundamentais à saúde, à alimentação adequada e ao meio ambiente ecologicamente equilibrado. Os princípios da precaução, da prevenção, do poluidor-pagador e da seletividade fornecem subsídios para a adoção de outro modelo de tributação e de governança que seja consentâneo com o interesse público. A tributação verde, a qual já é realidade em países que não irrelevam os riscos e os danos decorrentes do uso e consumo de agrotóxicos aos seres humanos e ecossistemas, desponta como um meio de efetivação do princípio fundamental da sustentabilidade. A concepção da Justiça Ecológica e seus três elementos revela parâmetros para a governança, para o processo de tomada de decisóes, bem como para o modelo de desenvolvimento verdadeiramente sustentável, em que esse adjetivo não seja tomado isoladamente. O ingresso da Defensoria Pública da União como custos vulnerabilis ou na condição de amicus curiae na Ação Direta de Inconstitucionalidade no 5553 assegura a representatividade de milhóes de pessoas vulneráveis, direta ou indiretamente afetadas com as isençóes fiscais a agrotóxicos e, concomitantemente, conferirá legitimidade democrática à decisão do Supremo Tribunal Federal.

Palavras-chave: Inconstitucionalidades. Isençóes tributárias. Agrotóxicos. Princípio fundamental da sustentabilidade. Tributação Verde.

\begin{abstract}
This article aims at identifying tax exemptions for pesticides in Brazil and analyzing the (un)constitutionality of these tax waivers, considering the fundamental rights to health, to adequate food and to an ecologically balanced environment. The principles of precaution, prevention, polluter-pays and selectivity provide subsidies for the adoption of another
\end{abstract}


model of taxation and governance aligned with the public interest. Green taxation, which is already a reality in countries that recognize the risks and damages resulting from the use and consumption of pesticides for humans and ecosystems, emerges as a means of implementing the fundamental principle of sustainability. The conception of Ecological Justice and its three elements shows parameters for governance, for the decision-making process and for the truly sustainable development model, in which this adjective is not considered isolately. The admission of Federal Public Defender's Office as custos culnerabilis or amicus curiae in the Direct Action of Unconstitutionality no 5553 ensures the representation of millions of vulnerable people, directly or indirectly affected by tax exemptions to pesticides and, concomitantly, will confer democratic legitimacy to the decision of the Federal Supreme Court.

Keywords: Unconstitutionalities. Tax exemptions. Pesticides. Fundamental principle of sustainability. Green taxation.

Data de submissão: 16/07/2020

Data de aceitação: 05/10/2020

\section{SUMÁRIO}

INTRODUÇÃO. 1. EXTRAFISCALIDADE ÀS AVESSAS E VIOLAÇÃO DO PRINCÍPIO CONSTITUCIONAL DA SELETIVIDADE. 2. OS IMPACTOS DOS AGROTÓXICOS À SAÚDE E AO MEIO AMBIENTE. 3. OFENSA A DIREITOS FUNDAMENTAIS. 4. PRINCÍPIO FUNDAMENTAL DA SUSTENTABILIDADE. 5. EXEMPLOS DE TRIBUTAÇÃO VERDE. CONSIDERAÇÓES FINAIS. REFERÊNCIAS.

\section{INTRODUÇÁO}

A partir da proibição de agrotóxicos nos países desenvolvidos, verificou-se uma corrida das empresas fabricantes dessas substâncias, a exemplo da Bayer/Monsanto, Dow-DuPont, Syngenta e Basf, em expandir seus mercados rumo a países considerados, na expressão de João Carlos Simóes Gonçalves Loureiro, "paraísos a-bioéticos".

Não foi à toa que, no Capítulo 19 da Declaração do Rio sobre Meio Ambiente e Desenvolvimento, conhecida como Agenda 21, resultado da Conferência das Naçóes Unidas sobre o Meio Ambiente e o Desenvolvimento (CNUMAD), foi reconhecido o grave contexto em que inseridos os países em desenvolvimento quanto à poluiçáo química em larga escala.

1 LOUREIRO, J. C. S. G. Constituiçáo e biomedicina: contribuição para uma teoria dos deveres bioconstitucionais na esfera da genética humana. 2003. Tese (Doutorado em Ciências Jurídico-Políticas) Universidade de Coimbra, Coimbra, 2003. 
No Brasil, por exemplo, o consumo de agrotóxicos corresponde a 19\% do mercado mundial $^{2}$ e, de acordo com o Instituto Brasileiro do Meio Ambiente e dos Recursos Naturais Renováveis (Ibama), na última atualização sobre a comerciação de agrotóxicos em 2016, entre os anos 2000 e 2014, o consumo de agrotóxicos triplicou ${ }^{3}$.

O consumo pelo brasileiro de uma grande quantidade de agrotóxicos também está atrelado ao número de agrotóxicos registrados anualmente pelo Ministério da Agricultura, Pecuária e Abastecimento (Mapa). Conforme o dossiê "Um alerta sobre os impactos dos agrotóxicos na saúde”, lançado em 2015 pela Associação Brasileira de Saúde Coletiva (Abrasco), "enquanto nos ultimos dez anos o mercado mundial de agrotoxicos cresceu 93\%, o mercado brasileiro cresceu 190\%. Em 2008, o Brasil ultrapassou os Estados Unidos e assumiu o posto de maior mercado mundial de agrotóxicos"

Citando dados do Instituto Brasileiro de Geografia e Estatística/Sistema IBGE de Recuperaçao Automática (IBGE/Sidra) e do Sindicato Nacional das Indústrias de Defensivos Agrícolas (Sindag), o citado Dossiê revela que, dos cerca de 853 milhóes de litros de agrotóxicos pulverizados em lavouras de soja, milho, cana, algodão, café, cítricos, frutas, eucaliptos, em 2011, a média de uso foi de 12 litros/hectare, representando uma exposicao media ambiental/ocupacional/alimentar de 4,5 litros de agrotóxicos por habitante, sendo comercializadas 823.226 toneladas de produtos químicos nas lavouras brasileiras no ano de 2012, movimentando US\$ 9,710 bilhóes 5 .

Outro fator que contribui para induzir o uso e consumo de agrotóxicos são as isençóes fiscais conferidas pelo Estado Brasileiro à comercialização e importação dessas substâncias. Sobre essa questão se debruça este artigo, ante a relevância do questionamento suscitado pelo Partido Socialismo e Liberdade - PSOL, por meio da Ação Direta de Inconstitucionalidade (ADI) 5553, bem como do debate jurídico-constitucional para toda a sociedade brasileira e, porquê não dizer, a sociedade global, também interessada.

A discussão na ADI 5553, em tramitação, consiste em avaliar se, à luz dos direitos fundamentais ao meio ambiente equilibrado (artigo 225 da CRFB/88), à saúde (artigo 196 da $\mathrm{CRFB} / 88$ ) e do princípio constitucional da seletividade tributária (artigos $153, \$ 3^{\circ}$, I, e $155, \$ 2^{\circ}$, III, da CRFB/88), devem subsistir a redução da base de cálculo do ICMS e a concessão de isenção de IPI incidentes sobre os agrotóxicos.

Nos termos do inciso I da Cláusula Primeira do Convênio no 100/97 do Conselho Nacional de Política Fazendária - CONFAZ, atualmente há uma redução de $60 \%$ da base de cálculo do Imposto sobre Circulação de Mercadorias e Prestação de Serviços (ICMS), nas saídas interestaduais de agrotóxicos.

\footnotetext{
2 BRASIL. Conselho Nacional de Segurança Alimentar e Nutricional da Presidência da República. E.M. no 003-2013, de $1^{\circ}$ de julho de 2013, 2013.

3 BRASIL. Instituto Brasileiro do Meio Ambiente e dos Recursos Naturais Renováveis. Relatórios de comercializaçáo de agrotóxicos, 2015.

${ }_{4}^{4}$ AUGUSTO, L. G. S. et al. (Org.). Dossiê Abrasco: um alerta sobre os impactos dos agrotóxicos na saúde, 2015, p. 49.

5 Ibid., p. 50; p. 451.
} 
Além disso, a mesma redução se aplica, nas operações internas com os agrotóxicos, consoante a Cláusula Terceira do Convênio no 100/97 do Conselho Nacional de Política Fazendária - Confaz.

Por sua vez, o Decreto 7.660, de 23 de dezembro de 2011 (substituído integralmente pelo Decreto 8.950/2016) concede isenção total do Imposto sobre Produtos Industrializados (IPI) para os agrotóxicos listados em tabela do próprio decreto.

Assinale-se que a Procuradoria-Geral da República já manifestou pela inconstitucionalidade dos dispositivos mencionados, em parecer favorável ao fim das isençóes de tributos aos agrotóxicos. Importante destacar, ainda, que a 4a Câmara do Meio Ambiente e Patrimônio Cultural do MPF promoveu uma Audiência Pública, em 27/06/2019, merecendo destaque a atuação do Procurador da República Marco Antônio Delfino de Almeida.

Também se manifestaram pela procedência da ação a Abrasco, o Instituto Brasileiro de Defesa do Consumidor (Idec), a Terra de Direitos, a Fian Brasil (Organização pelo Direito Humano à Alimentação e à Nutrição Adequadas), a Campanha Nacional em Defesa da Vida e Contra os Agrotóxicos, a Associação Brasileira de Agroecologia (ABA) e a Defensoria Pública do Estado de São Paulo.

Diante das isençóes tributárias incidentes sobre os agrotóxicos e dos bilhóes de reais que não são arrecadados anualmente aos cofres públicos, este artigo se propóe a: identificar a deturpação do princípio tributário da seletividade; a enumerar as violaçóes a direitos fundamentais decorrentes; a avaliar os impactos desses produtos químicos, mediante constataçóes científicas e condenaçóes judiciais de empresas fabricantes/comerciantes de agrotóxicos; a investigar a existência de alternativas viáveis a esse modelo como derivação do princípio fundamental da sustentabilidade, concebido por Klaus Bosselmann como um dos pilares da sociedade moderna, tal como a justiça, a igualdade e a liberdade ${ }^{6}$; e, por fim, a sugerir o ingresso da Defensoria Pública da União na condição de custos vulnerabilis ou amicus curiae na ADI 5553, em razão da representação adequada dos assistidos vulneráveis, cujos direitos são colocados em xeque, inclusive intergeracionalmente, pelos danos advindos dos uso e consumo de agrotóxicos.

\section{EXTRAFISCALIDADE ÀS AVESSAS E VIOLAÇÁO DO PRINCÍPIO CONSTI- TUCIONAL DA SELETIVIDADE}

Na questão posta em discussão, impende compreender inicialmente a extrafiscalidade e o princípio da seletividade dos tributos.

Quanto à primeira, Paulo de Barros Carvalho ensina que se caracteriza pelo "emprego de fórmulas jurídico-tributárias para a obtenção de metas que prevalecem sobre os fins simplesmente arrecadatórios de recursos monetários" 7 . Hugo de Brito Machado assevera que "o tributo é extrafiscal quando seu objetivo principal é a interferência no domínio

${ }^{6}$ BOSSELMANN, K. The principle of sustainability: transforming law and governance, 2008, p. 5.

7 CARVAlHO, P. de B. Curso de direito tributário, 2011, p. 291. 
econômico, para buscar um efeito diverso da simples arrecadação de recursos financei-

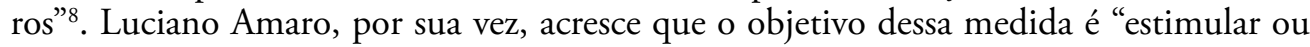
desestimular certos comportamentos, por razóes econômicas, sociais, de saúde etc" .

Roque Antônio Carraza, ao esclarecer que o IPI e o ICMS devem guardar o caráter extrafiscal, explicita o princípio da seletividade:

Os tributos, de um modo geral, são utilizados como instrumento de fiscalidade, servindo basicamente, pois, para carrear dinheiro aos cofres públicos. O IPI e o ICMS, pelo contrário, devem necessariamente ser instrumentos de extrafiscalidade, a teor dos já citados arts. $153, \$ 3^{\circ}$, I e $155, \$ 2^{\circ}$, III, da CF. Salientamos que estas normas constitucionais, mandando que tais impostos sejam seletivos, não estáo dando uma mera faculdade ao legislador, mas, pelo contrário, estão lhe impondo um inarredável dever, de cujo cumprimento ele não pode se furtar. (...) Portanto, a seletividade, no IPI e no ICMS, é obrigatória. $\mathrm{Ou}$, seguindo a trilha constitucional, estes tributos devem ser seletivos, em funçáo da essencialidade do produto industrializado (IPI) ou das mercadorias ou serviços (ICMS). Estamos confirmando, destarte, que o IPI e o ICMS devem ser utilizados como instrumentos de ordenação político-econômica, estimulando a prática de operaçóes (com produtos industrializados ou mercadorias) ou serviços havidos por necessários, úteis ou convenientes à sociedade e, em contranota, onerando outros que não atendam tão de perto o interesse coletivo ${ }^{10}$.

Em função disso, o Parecer da Procuradoria-Geral da República critica a concessão de isenção fiscal aos agrotóxicos, haja vista que estes não podem ser considerados produtos essenciais, na CRFB $/ 88^{11}$.

Nesse ponto, impende destacar a lição de Klaus Bosselmann de que, na tomada de decisóes e na aplicação de princípios, devem ser consideradas as partes interessadas e afetadas, com vistas a se pautar no interesse público ou nacional ou, na melhor expressáo cunhada por ele, no "interesse de toda a comunidade", consubstanciado nos interesses coletivos de longo prazo das geraçóes presentes e futuras do ser humano e de outras espécies ${ }^{12}$.

Considerado o princípio da seletividade, bem como a extrafiscalidade, dever-se-ia impor tributação mais elevada aos agrotóxicos, e não a isenção fiscal a esses produtos, uma vez que além de não serem essenciais para a vida da população, seu uso e consumo deveria ser desestimulado, em contraposição ao estado atual de "extrafiscalidade às avessas", em que se estimula um modelo de produção insustentável.

\footnotetext{
${ }^{8}$ MACHADO, H. de B. Curso de direito tributário, 2009, p. 96.

9 AMARO, L. Direito tributário brasileiro, 2011, p. 111.

10 CARRAZA. R. A. Curso de direito constitucional tributário, 2004, p. 89-90.

11 BRASIL. Procuradoria-Geral da República. Parecer na ADI 5553, 2017, p. 42.

12 BOSSELMANN, K. Op. Cit., p. 176.
} 
Incompatíveis com os objetivos fundamentais da República, os benefícios fiscais concedidos aos agrotóxicos, somente em 2017, se aproximaram de 10 bilhóes de reais, "sendo que o tributo responsável pelo maior montante desonerado em 2017 foi o ICMS, com 63,1\% do total. Em seguida, o IPI com 16,5\%, as contribuiçóes sociais Pis/Pasep e Cofins, com $15,6 \%$ e, por último e com o menor montante, o imposto de importaçáo com 4,8\%"13.

Nesse relatório produzido pela Abrasco, com base nos dados do censo agropecuário 2017, da Secex (2017), Receita Federal (2017) e da legislação tributária federal e estadual, concluiu-se que os 3,6 bilhóes da desoneração que impactam diretamente o orçamento federal correspondem a cerca de $10 \%$ do orçamento da agricultura ${ }^{14}$.

Vale dizer tamanha renúncia fiscal não se coaduna com o discurso de austeridade fiscal, sobretudo se se condiderar que o modelo químico-dependente não é eficiente e tampouco sustentável, pois, além de demandar cada vez mais agrotóxicos, exige como medida compensatória a expansão das áreas de cutivo e, por conseguinte, o desmatamento.

Sobreleva, ainda, o fato de que essa renúncia fiscal sinaliza que o Estado Brasileiro não leva os direitos a sério. Todo direito exige uma prestação positiva, não sendo possível cogitar em efetivação de direitos sem os devidos recursos advindos de tributos:

All rights are claims to an affirmative governmental response. All rights, descriptively speaking, amount to entitlements defined and safeguarded by law. [...]

All rights are costly because all rights presuppose taxpayer funding of effective supervisory machinery for monitoring and enforcement.

The most familiar government monitors of wrongs and enforcers of rights are the courts themselves. [...]

The financing of basic rights through tax revenues helps us see clearly that rights are public goods: taxpayer-funded and government-managed social services designed to improve collective and individual well-being. All rights are positive rights ${ }^{15}$.

Além do desmantelamento da política de segurança alimentar, o desalinhamento de políticas públicas, evidenciado na governança das desoneraçóes tributárias, implicou em uma série de recomendaçóes pelo Plenário do TCU, no Acórdão 709/2018, ao avaliar a preparação do Governo Brasileiro para implementar a Agenda 2030 e a meta 2.4 dos Objetivos de Desenvolvimento Sustentável (ODS) no Brasil, especialmente o ODS 2 "Fome Zero e Agricultura Sustentável"16.

${ }^{13}$ CUNHA, L. N. da.; PORTO, M. F. de S.; SOARES, W. L. Uma política de incentivo fiscal a agrotóxicos no Brasil é injustificável e insustentável: relatório produzido pela Abrasco através do GT Saúde e Ambiente, com o apoio do Instituto Ibirapitanga, 2020, p. 5.

14 Ibid., p. 6.

15 HOLMES, S.; SUNSTEIN, C. R. The cost of rights: why liberty depends on taxes, 1999, p. 44; p. 48.

16 BRASIL. Tribunal de Contas da Uniāo. Acórdáo 709/2018 Plenário. Relator Augusto Nardes. Processo 029.427/2017-7, 2018. 
Frise-se que, ao se observar a ratio da extrafiscalidade e do princípio da seletividade, o Estado deveria incentivar a agricultura familiar e camponesa, a qual responde por $70 \%$ dos alimentos in natura consumidos ${ }^{17}$, bem como a pesquisa e expansáo de alimentos seguros, trocando a isenção fiscal sobre agrotóxicos pela isenção sobre alimentos orgânicos e biodinâmicos, os quais sim guardam o caráter de essencialidade à manutenção da vida e do meio ambiente.

\section{OS IMPACTOS DOS AGROTÓXICOS À SAÚDE E AO MEIO AMBIENTE}

Não bastasse o elevado montante de recursos, os quais deixam de ser arrecadados e aplicados na consecuçáo dos objetivos fundamentais da República, merece destaque que os danos e as externalidades negativas provocados pelos agrotóxicos são transferidos à sociedade e ao meio ambiente, em razão da inobservância do princípio do poluidor-pagador, o qual determina que, "no caso do consumidor de um produto transformado, cuja produção foi poluente, o poluidor-que-deve pagar é que efectivamente cria e controla as condições em que a poluição, e só ele dispóe de meios para evitar" ${ }^{18}$.

A respeito das externalidades associadas ao uso de agrotóxicos, o custo para a saúde do trabalhador rural e dos consumidores pode ser externado nas intoxicaçóes agudas, na redução da fertilidade, nos distúrbios hormonais e comportamentais, em efeitos teratogênicos, mutagênicos e carcinogênicos.

Quanto ao custo ambiental gerado por essas substâncias nocivas, citem-se a contaminação da água, do ar e do solo e, em relaçáo à biota, verifica-se verdadeiro desequilíbrio ecológico com a extinção de espécies e comprometimento da polinização e da biodiversidade.

Essas externalidades são potencializadas quanto mais os ingredientes das formulaçóes de agrotóxicos comercializadas são camuflados como "inertes", ou seja, cujas identidades não são reveladas sob o manto do segredo empresarial das empresas formuladoras ${ }^{19}$.

Passa-se doravante a explicitar alguns desses impactos citados, em que pese se estar diante de subnotificações de contaminação por agrotóxicos.

Conforme ressalva Larissa Bombardi, de 2007 a 2014 foram 25 mil intoxicaçóes por agrotóxicos notificadas junto ao Ministério da Saúde. Náo obstante, se calcula que, para cada caso de intoxicaçáo notificada, tenham-se 50 outros náo notificados, o que denota uma notificação estimada em apenas a $2 \%$ dos números reais ${ }^{20}$.

17 AUGUSTO, L. G. S. et al. (Org.). Op. Cit., p. 281.

18 ARAGÃO, A. O princípio do poluidor pagador: pedra angular da política comunitária do ambiente, 2014, p. 136.

19 VANDERLEI, M. R. Efeitos dos agrotóxicos Kraft ${ }^{\circledR}$ 36EC e Score ${ }^{\circledR} 250 \mathrm{EC}$ (e seus princípios ativos) em ecossistemas aquáticos: análises comparativas e ecossistêmicas. 2015. Dissertação (Mestrado em Engenharia Ambiental) - Universidade de São Paulo, São Carlos, 2015. p. 23.

${ }_{20}$ BOMBARDI, L. M. Geografia do uso de agrotóxicos no Brasil e conexóes com a Uniáo Europeia, 2017, p. 54. 
Raquel Maria Rigotto ilustra que o "Estudo epidemiológico da população da região do Baixo Jaguaribe/CE exposta à contaminação ambiental em área de uso de agrotóxicos", realizado pela Universidade Federal do Ceará, registrou aumento de $100 \%$ dos agrotóxicos consumidos no Ceará entre 2005 e 2009 e de 963,3\% dos ingredientes ativos comercializados no estado no período. A pesquisa ainda realça a contaminação da água disponibilizada para consumo e dos lençóis freáticos, ao que se soma:

o lançamento de cerca de 4.425.000 litros pela pulverização aérea de calda contendo venenos extremamente tóxicos e altamente persistentes no ambiente do entorno de comunidades da Chapada do Apodi/ CE e a exposição diária de trabalhadores do agronegócio a elevados volumes de caldas tóxicas, que inclusive já resultou em pelo menos um óbito e na identificação de alteraçóes na função hepática de significativo contingente de trabalhadores examinados. Constatou-se que os agricultores no Ceará têm até seis vezes mais câncer do que os não agricultores, em pelo menos 15 das 23 localizaçóes anatômicas estudadas. Além disso, a taxa de mortalidade por neoplasias foi $38 \%$ maior (IC95\%=1,09-1,73) nos municípios de estudo. ${ }^{21}$

Um caso emblemático marcou a comprovação do nexo causal entre o agrotóxico e o câncer que causou a morte de Vanderlei Matos da Silva, no Ceará, o que resultou na condenação da empresa Del Monte Fresh Produce pela Justiça do Trabalho ${ }^{22}$.

Sobre os efeitos nocivos da pulverização aérea, cite-se o caso da contaminação ocorrido em uma escola municipal de Rio Verde/GO:

A pulverização aérea de agrotóxicos é responsável pelo relato de sintomas característicos de intoxicaçóes agudas e crônicas por comunidades locais, incluindo principalmente náuseas, cefaleia, dificuldades respiratórias e alergias cutâneas. Entre os casos mais graves de intoxicaçóes causadas por pulverização aérea de agrotóxicos no Brasil está o do município de Rio Verde/GO, onde uma escola municipal foi diretamente atingida, causando a intoxicaçáo aguda de 92 pessoas, a maioria crianças e adolescentes, conforme consta no Sistema de Informação sobre Agravos de Notificação (Sinan). Os principais sintomas relatados foram náuseas, vômitos, tonturas, cefaleias, convulsôes e irritação na pele. ${ }^{23}$

A presença de agrotóxicos na água, por sua vez, revela que os ambientes de água doce são um dos ecossistemas mais atingidos, não só pelo comprometimento da biota aquática, como em decorrência da insegurança alimentar gerada pelo consumo da água contaminada.

\footnotetext{
${ }^{21}$ RIGOTTO, R. M. Agrotóxicos, trabalho e saúde: vulnerabilidade e resistência no contexto da modernização agrícola no Baixo Jaguaribe/CE, 2011.

22 ARANHA, A. Multinacional é condenada por morte de trabalhador contaminado por agrotóxicos. Repórter Brasil, 2018.

${ }^{23}$ BRASIL. Departamento de Vigilância em Saúde Ambiental e Saúde do trabalhador do Ministério da Saúde do Brasil. Nota informativa contendo esclarecimentos sobre pulverizaçáo aérea e o controle de endemias, 2016.
} 
A gravidade da contaminaçấo dos alimentos pode ser ilustrada após pesquisa inédita da Universidade Federal de Goiás (UFG), em parceria com a Universidade de Louisiana, dos Estados Unidos, publicada em 2019, que revelou a impossibilidade de se retirar o agrotóxico do alimento antes do consumo. Durante o experimento, foi aplicado um fungicida na casca de uma maçã orgânica e a fruta foi analisada em um aparelho normalmente utilizado para rastrear células cancerígenas. Com o passar dos dias, foi constatado que o fungicida penetrava cada vez mais na polpa da fruta, sendo que, em uma semana, havia avançado três milímetros e, em outro exame, com infravermelho, o agrotóxico penetrou 6 milímetros na polpa da fruta ${ }^{24}$.

Mister relembrar que a correlação entre os agrotóxicos e os danos à saúde e ao meio ambiente foi denunciada por Rachel Carson, na obra Primavera Silenciosa, em 1962, ao observar a incomum mortandade de pássaros, à época devido à ação do DDT e de outros organoclorados ${ }^{25}$. A coragem da cientista em trazer à tona as contradiçóes do uso de agrotóxicos foi um grande legado para o aumento da consciência ecológica e das responsabilidades que guardamos em relação à espécie humana e a todas as demais.

\section{OFENSA A DIREITOS FUNDAMENTAIS}

Depreende-se dos danos gerados à saúde dos trabalhadores rurais e dos consumidores que os agrotóxicos e as desoneraçóes tributárias a estes vinculadas importam em afronta direta ao direito fundamental à saúde e à garantia constitucional de que o Estado deve, "mediante políticas sociais e econômicas", reduzir o risco de doença e de outros agravos, nos termos dos artigos $6^{\circ}$ e $196 \mathrm{da}$ CRFB/88.

O reflexo do uso de agrotóxicos é a sobrecarga do Sistema Único de Saúde, porquanto, de acordo com pesquisa da FIOCRUZ, para cada dólar gasto com a compra dos agrotóxicos no Estado do Paraná, cerca de US\$ 1,28 são gerados em custos de saúde apenas para casos de intoxicação ${ }^{26}$.

Outra violação decorrente das desoneraçóes das isenções fiscais incidentes sobre agrotóxicos remete ao direito fundamental à alimentaçâo, haja vista o estado de insegurança alimentar e nutricional gerado, em razão de o Estado inobservar o dever de garantir as dimensóes indivisíveis e indissociáveis do direito à alimentaçáo, quais sejam o direito de cada pessoa de estar livre da fome e da má nutrição e o direito à alimentação adequada.

\footnotetext{
${ }^{24}$ LUQUESI, T.; TÚLIO, S. Pesquisa da UFG, em parceria com uma universidade da Louisiana, nos EUA, concluiu que agrotóxico penetra além da casca da maçã. G1 Goiás, 2016.

25 CARSON, R. Primavera silenciosa, 2010.

26 SOARES. W. L. Uso dos agrotóxicos e seus impactos à saúde e ao ambiente: uma avaliação integrada entre a economia, a saúde pública, a ecologia e a agricultura. 2009. Tese (Doutorado em Saúde Pública e Meio Ambiente) - Escola Nacional de Saúde Pública Sergio Arouca, Fundação Osvaldo Cruz, Rio de Janeiro, 2009. p. 63.
} 
O Conselho Nacional de Segurança Alimentar e Nutricional (CONSEA) ${ }^{27}$ já havia taxado o uso de agrotóxicos como uma das mais severas violaçóes a esse direito, o qual foi previsto constitucionalmente somente após a Emenda Constitucional no 64/2010, mas que antes já encontrava salvaguarda na Declaração Universal dos Direitos Humanos, no Pacto Internacional sobre os Direitos das Crianças e no Pacto Internacional dos Direitos Econômicos, Sociais e Culturais (PIDESC) e no Protocolo Adicional à Convenção Americana sobre Direitos Humanos na área de Direitos Econômicos, Sociais e Culturais de 1988 (Protocolo as São Salvador).

Cumpre mencionar, ainda, como desdobramento das desoneraçóes tributárias, a violação ao direito ao meio ambiente ecologicamente equilibrado, com previsão no artigo 225 da $\mathrm{CRFB} / 88$, o qual contemplou o que a doutrina denomina de "Estado de Direito Ambiental", diante da necessidade de tutela adequada de bem de uso comum do povo e essencial à sadia qualidade de vida, em observância aos princípios da prevenção e precaução ${ }^{28}$.

Depreende-se que a sociedade se depara com malefícios outros que não apenas as ameaças às liberdades, tendo em vista que riscos de repercussão geral e indistinta colocam em xeque a denominada segurança ambiental, conforme se refere o Ministro do Superior Tribunal de Justiça, Antônio Herman de Vasconcellos e Benjamin ${ }^{29}$. Para garantir o direito ao meio ambiente ecologicamente equilibrado a todos, o qual é intrínseco ao direito à vida, à segurança alimentar e à dignidade, devem o Poder Público e a coletividade defendê-lo e preservá-lo progressivamente, e não retrocedendo.

À luz dos princípios da prevenção e da precaução, não bastassem os danos relacionados a agrotóxicos já conhecidos, importa realçar que o mero risco e incerteza de outras externalidades negativas e "um sistema de gerenciamento de riscos que ignora a incerteza e a expectativa de danos não quantificáveis consiste em verdadeira receita para os desastres" 30 .

Conforme ensina Édis Milaré, considera-se a incidência do princípio da prevenção para tratar de "riscos ou impactos já conhecidos pela ciência", de sorte que o princípio da precaução, por sua vez, deve ser invocado quando "a informação científica é insuficiente, inconclusiva ou incerta e haja indicaçóes de que os possíveis efeitos sobre o ambiente, a saúde das pessoas ou dos animais ou a proteção vegetal possam ser potencialmente perigosos e incompatíveis com o nível de proteção escolhido", o que significa que "a incerteza científica milita em favor do ambiente, carreando-se ao interessado o ônus de provar que

\footnotetext{
27 Órgão de assessoramento imediato ao Presidente da República e que era responsável, em regime de colaboração com os demais integrantes do Sistema Nacional de Segurança Alimentar e Nutricional (Sisan), pela articulação, acompanhamento e monitoramento da implementação e da convergência de açóes inerentes à Política e ao Plano Nacional de Segurança Alimentar e Nutricional. A despeito da importância das suas atribuições, o Consea foi extinto pela Medida Provisória no 870/2019.

28 MACHADO, P. A. L. Direito ambiental brasileiro, 2014, p. 94-117.

${ }^{29}$ BENJAMIN, A. H. V. e. Meio ambiente e constituição: uma primeira abordagem. In: CONGRESSO INTERNACIONAL DE DIREITO AMBIENTAL, 2002. Anais..., 2002, p. 89.

30 CARVALHO, D. W. de. Desastres ambientais e sua regulação jurídica: deveres de prevenção, respostas e compensação ambiental, 2015.
} 
as intervenções pretendidas não trarão consequências indesejadas ao meio considerado”. Alerta o autor, ainda, que:
a omissão na adoção de medidas de precaução, em caso de risco de dano ambiental grave ou irreversível, foi considerada pela Lei $\mathrm{n}^{\circ}$ 9.605/1998 (Lei dos Crimes Ambientais) como circunstância capaz de sujeitar o infrator a reprimenda mais severa, idêntica à do crime de poluição qualificado pelo resultado $\left(\operatorname{art} .54, \S 3^{\circ}\right) .^{31}$

Com efeito, a CRFB/1988, no artigo 225, caput e $₫ 1^{\circ}$, V e VII, ao invés de uma proteção por ricochete, em que o bem jurídico tutelado era outro (o patrimônio, por exemplo) e só de forma reflexa atingisse o meio ambiente, passou a considerar este como um bem em si mesmo, dotado de autonomia, em que qualquer resultado a ser buscado deve ser in dubio pro natura.

Diante da supressão da proteção a direitos fundamentais consagrados e consolidados na ordem jurídica brasileira e do grave retrocesso ecológico que permeia a concessão de isençóes tributárias sobre agrotóxicos, impende citar a jurisprudência do Supremo Tribunal Federal, que poderá informar as balizas para o julgamento da ADI 5553.

No julgamento da medida cautelar em ADI 3.540-1, o Ministro Relator Celso de Mello sustentou que o direito à preservaçáo da integridade do meio ambiente consiste em uma prerrogativa qualificada por seu caráter de metaindividualidade, sendo inarredáveis as obrigaçóes do Estado em não retroceder e em avançar na proteção do meio ambiente e da saúde humana.

Vale lembrar, em importante voto da Ministra Cármen Lúcia, quando votou pela procedência da ADI 5592, a intrínseca relação do princípio da proteção ao meio ambiente com o direito fundamental à saúde, uma vez que, de acordo com a ilustre Ministra, a alteraçáo no equilíbrio do ecossistema e o prejuízo ao desenvolvimento sustentável afetam o ser humano.

Além disso, a Ministra alertou, ao tratar da dispersão de substâncias químicas por aeronaves para combate ao mosquito transmissor do vírus da dengue, do vírus chikungunya e do vírus da zika, que "na nova ordem mundial, deve-se adotar como política pública o que for necessário para antecipar-se aos riscos de danos que se possam causar ao meio ambiente. Não se resolve crise na saúde pública com a criação de outra crise, também gravosa à saúde das pessoas e ao meio ambiente" 32 .

\section{PRINCÍPIO FUNDAMENTAL DA SUSTENTABILIDADE}

Sustentabilidade, para José Afonso da Silva, possui fundamento constitucional, com respaldo no artigo 225 da CRFB/88 e deriva da imposição do dever ao Poder Público e à

\footnotetext{
31 MILARÉ, É. Direito do ambiente, 2015, p. 263-266.

32 BRASIL. Supremo Tribunal Federal. Tribunal Pleno. ADI 5592. Relatora: Ministra Cármen Lúcia. Relator para Acórdão: Ministro Edson Fachin. Brasília, DF, de 11 de setembro de 2019. Brasília, DF: STF, 2019. Disponível em: <http://redir.stf.jus.br/paginadorpub/paginador.jsp?docTP=TP\&docID=752184165>. Acesso em: 29 jun 2020.
} 
coletividade de defender e preservar o direito ao meio ambiente ecologicamente equilibrado para as presentes e futuras geraçóes. Acrescenta que não há crescimento econômico sustentável sem equitativa redistribuição dos resultados do processo produtivo, sem a erradicação da pobreza e sem o atendimento das necessidades da populaçãa ${ }^{33}$.

Assim como os ideais de justiça e de direitos humanos, a sustentabilidade consiste em um ideal de civilizaçáo, tanto em nível nacional quanto internacional. Além de ser qualificado como princípio do direito internacional, sustentabilidade é um princípio fundamental, como alguns outros pilares da sociedade moderna: justiça, igualdade e liberdade, cujos significados são impactados pelo princípio da sustentabilidade, devido à sua dimensão espacial e temporal mais ampla ${ }^{34}$.

Para Klaus Bosselmann, o documento mais profundo e importante para reconhecer a importância fundamental da sustentabilidade, com vistas a definir uma estrutura para a construção de uma sociedade gobal no século XXI que seja justa, sustentável e pacífica, é a Carta da Terra ${ }^{35}$. Referido documento finalizado em 2000 foi subscrito pelo Brasil e contempla diretrizes relevantes para a enfrentamento das desoneraçóes tributárias a agrotóxicos e para a adequada forma de produzir alimentos.

Todos esses mandamentos consubstanciam o respeito à Terra e à vida em toda a sua biodiversidade, bem como contemplam o verdadeiro significado da sustentabilidade, por reconhecer que todos os seres são interdependentes e que toda forma de vida tem valor, além de se depositar fé na dignidade e no potencial dos seres humanos ${ }^{36}$.

De acordo com Klaus Bosselmann, a humanidade não progredirá na busca por sustentabilidade se continuar separando os "fatos" científicos dos "valores" éticos. Ademais, se persistir a governança ambiental como o primo pobre da governança econômica, o conceito de desenvolvimento sustentável continuará uma promessa não cumprida. Nesse sentido, o autor citado defende que a aplicação do princípio da sustentabilidade, núcleo conceitual do desenvolvimento sustentável, está condicionada a que esse princípio se torne um paradigma abrangente do direito e da governança, colocando a jurisprudência e as instituiçóes legislativas em um novo caminho ${ }^{37}$.

Para tanto, o princípio da sustentabilidade fornece orientaçóes importantes para tornar o conceito holístico de desenvolvimento sustentável operacional, haja vista que esse princípio, ao imprimir o dever de proteger e restaurar a integridade dos sistemas ecológicos da Terra, demanda ação ("proteger e restaurar") e, por conseguinte, é capaz de causar efeito legal, ou seja, trata-se de norma que cria a obrigação de promover prosperidade econômica de longo prazo e justiça social dentro dos limites da sustentabilidade ecológica ${ }^{38}$.

33 SILVA, J. A. da. Direito ambiental constitucional, 2010, p. 24-26.

34 BOSSELMANN, K. Op. Cit., p. 4-5; p. 62.

35 Ibid., p. 57.

36 Ibid., p. 75.

37 Ibid., p. 4; p. 7.

38 Ibid., p. 53. 
Como existem escolhas a serem feitas entre necessidades concorrentes e sobre a extensão dessa "integração" e proteção dos sistemas ecológicos, surgem questôes de justiça distributiva. Por essa razão, o autor desenvolve o conceito de Justiça Ecológica com 3 elementos éticos: justiça intrageneracional, intergeracional e interespécies, em uma visão ecocêntrica ao invés de antropocêntrica, ao considerar que a manutenção da integridade ecológica dos ecossistemas está atrelada à responsabilidade pelos demais seres vivos, agregando essa preocupação com o mundo natural não humano (interspecies justice) à preocupação com os pobres (intragenerational justice or equity) e à preocupação com o futuro (intergenerational justice or equity) ${ }^{39}$ :

To become a truly ecological concept, justice needs to reach out into the non-human world. As we will see, the 'missing link' in both the sustainable development debate and the justice debate is the recognition of ecological integrity. It is not enough to care for humans living today and those living tomorrow when the natural processes that sustain life are at risk. There is a need to identify and recognize the ethical and legal importance of ecological integrity. ${ }^{40}$

Em contraposição à alienação e separação em relaçáo ao mundo natural não humano, característica dominante da modernidade, Klaus Bosselmann relembra os estreitos laços entre ética, justiça e direito do início da civilização moderna, em que Aristóteles elencou algumas virtudes associadas a uma boa vida: imaginação, abertura e empatia, sem as quais é razoável sugerir que a pessoa é indiferente em relação a outros seres humanos e à vida não humana a seu redor. Insta ressaltar que não há contradição entre a empatia pelo mundo natural e a boa vida dos seres humanos e que a tragédia da modernidade tem sido criar a dicotomia entre autonomia e dependência, sendo que necessitamos sobremaneira de um senso sofisticado de interdependência humana, porquanto "a sense of interconnectedness may well be the key for future decision-making"'t1.

Essa necessária visão holística representada na construção da conexão essencial entre o pensar, o querer e a ação pode ser depreendida também da contribuição de Ana Primavesi, precursora da agroecologia no Brasil e para quem o manejo ecológico de solos e águas é a única alternativa verdadeiramente sustentável ante a atual situação de degradação ${ }^{42}$.

No XV Congresso Internacional de Nutrição Funcional, em São Paulo/SP, promovido pela VP Centro de Nutrição Funcional, em 13/09/2019, o Professor Geraldo Deffune, Engenheiro Agrônomo (ESALQ-USP), M.Sc., Ph.D. (Univ. of London), durante a palestra "Agroecologia Aplicada, Biodinâmica e Biossegurança", apresentou os "Resultados da Pesquisa Comparativa de Produtividade, Qualidade Nutricional e Vitalidade de Alimentos Biodinâmicos e Convencionais", bem como mencionou a seguite reflexão de Rudolf Steiner, criador da agricultura biodinâmica, resultante de um diálogo com Ehrenfried Pfeiffer, a qual pode ser conferida no prefácio do livro "Agriculture Course":

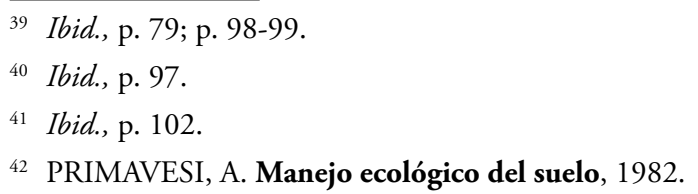


This is a problem of nutrition. Nutrition as it is today does not supply the strength necessary for manifesting the spirit in physical life. A bridge can no longer be built from thinking to will and action. Food plants no longer contain the forces people need for this. ${ }^{43}$

Administrar a unidade agrícola como um "todo orgânico" ("a dynamic living organic who$l e$ ”), regulado pelo equilíbrio entre as espécies e a saúde humana, ambiental e socioeconômica, foi inicialmente concebido pelo agrônomo Lord Northbourne, influenciado por Steiner, em 1940, na obra "Look to the Land", no qual introduziu o termo "agricultura orgânica" no mundo ${ }^{44}$.

Verifica-se, portanto, a consonância dessa visão com a ideia central do princípio da sustentabilidade, enquanto princípio de direito e de governança, consistindo, segundo Klaus Bosselmann, como a habilidade de respeitar e manter a integridade ecológica do planeta ${ }^{45}$.

Tomada a sustentabilidade como fundamental para o projeto de civilização, Klaus Bosselmann destaca que, na omissão do Estado e das instituiçóes, cumpre à sociedade civil desenvolver a agenda desse princípio, no que denomina a cidadania como principal veículo e catalisador para a mudança política ${ }^{46}$.

Ao informar e definir as funçóes internas e externas do Estado, o princípio da sustentabilidade rechaça qualquer ação ou omissão que coloque em risco ou provoque danos à integridade ecológica, seja para as presentes e futuras geraçóes, seja para as demais espécies que integram o chamado "todo orgânico". Não se concebe, dessarte, o Estado estimular o uso de agrotóxicos mediante a concessão de incentivos fiscais.

\section{EXEMPLOS DE TRIBUTAÇÁO VERDE}

Conforme esclarece Regina Helena Costa, a tributação ambiental consiste no emprego de instrumentos tributários para gerar os recursos necessários à prestação de serviços públicos de natureza ambiental, o que se relaciona à função fiscal do tributo, e também para orientar o comportamento dos contribuintes à proteção do meio ambiente, o que sobreleva o caráter extrafiscal tributário ${ }^{47}$. Nesse sentido Heleno Taveira Torres ensina:

A tentativa de construção de um Sistema Tributário Ambiental tem sido permanentemente referida como um dos principais instrumentos do desenvolvimento econômico sustentável, com o propósito de

${ }^{43}$ STEINER, R. Agriculture course: the birth of the biodynamic method. Rudolf Steiner Archive \& e.Lib, 2007.

44 SCOFIELD, A. M. Organic farming: the origin of the name. Biological Agriculture and Horticulture, p. 1-5, 1986.

45 BOSSELMANN, K. Op. Cit., p. 2.

46 Ibid., p. 3-4.

47 COSTA, R. H. Apontamentos sobre a tributação ambiental no Brasil. In: TORRES, H. T. (Org.). Direito tributário ambiental, 2005, p. 313. 
alcançar uma efetiva "economia verde" (green economy). De fato, os tributos, em suas distintas técnicas de aplicação, podem ser usados para reduzir ou eliminar externalidades ambientais, estimular a inovação e assegurar proteção ao meio ambiente, numa interação permanente com o aprimoramento da educação, da reduçáo da pobreza e da melhoria da qualidade de vida da população. ${ }^{48}$

Em havendo formas de produção de alimentos que não ameacem e tampouco gerem risco ao meio ambiente, justifica-se a concessão de desoneraçóes tributárias. Não obstante, o direito tributário não pode incentivar a erosão genética e a agressão à biodiversidade ocasionada pela monocultura e uso de agrotóxicos, sendo que se estima que a taxa anual da extinção de espécies causadas pela ação humana é de 50 a 100 vezes superior aos índices por causas naturais ${ }^{49}$. Diante desse cenário, José Joaquim Gomes Canotilho ensina:

\begin{abstract}
as agressóes ao direito ao ambiente, traduzidas sobretudo na perturbação da integridade dos componentes ambientais naturais, carecem de justificação adequada caso se trate também de restriçóes ao núcleo essencial do direito ao ambiente e qualidade de vida na sua dimensão de direito, liberdade e garantia. Dentre as ponderaçóes a incluir na justificação adequada deve incluir-se o juízo sobre alternativas ambiental e ecologicamente amigas, desde que elas se revelem adequadas, necessárias e proporcionais..$^{50}$
\end{abstract}

A chamada "governança para sustentabilidade" deve refletir nossas relaçóes ecológicas, tendo em conta o novo ponto focal: a comunidade mais ampla da vida e o intrínseco valor dos ecossistemas. Klaus Bosselmann destaca que o principal texto de direito ambiental da Nova Zelândia é inspirado na Carta da Terra ("importance of non-human ecology or broad biodiversity" e "earth guardianship and trusteeship principles"), o que demonstra as sinergias entre ética, direito e governança ${ }^{51}$.

Durante a audiência pública promovida pela $4^{\mathrm{a}}$ Câmara do Meio Ambiente e Patrimônio Cultural do MPF, sobre a ADI 5553, em 27/06/2019, em Brasília/DF, MinistraConselheira da Embaixada Real da Dinamarca, Laura Nielsen destacou a governança dinamarquesa em torno das desoneraçóes tributárias e as políticas públicas adotadas, denotando caminho bastante diverso da realidade brasileira.

Para que a Dinamarca se tornasse o país com maior participação de produtos orgânicos no mercado (cerca de $10 \%$ da agricultura dinamarquesa é orgânica), a Ministra assinalou a confluência de fatores: a) estabelecimento de uma parceria sólida entre os agricultores, produtores e consumidores; b) desenvolvimento de uma legislação na área de agricultura

\footnotetext{
48 TORRES, H. T. Descompasso entre as políticas ambiental e tributária, 2012.

49 MACHADO, L. C. P.; MACHADO FILHO, L. C. P. A dialética da agroecologia: contribuição para um mundo com alimentos sem veneno, 2014, p. 82.

50 CANOTILHO, J. J. G. O princípio da sustentabilidade como princípio estruturante do direito constitucional. Tékhne: Revista de Estudos Politécnicos, p. 7-18, 2010.

51 BOSSELMANN, K. Op. Cit., p. 176-177.
} 
e produção orgânica, em 1987, acompanhada de uma série de planos de açóes públicas com a meta de expandir a produçáo orgânica na Dinamarca, bem como aumentar as exportaçóes desses produtos, o que incentivou os fazendeiros quando perceberam a demanda; c) investimento em pesquisa na área de desenvolvimento do setor orgânico pelo Estado Dinamarquês, que deu excelente exemplo, ao prover de alimentos orgânicos as instituiçóes públicas como hospitais, asilos e creches; d) concessão de subsídios públicos para incentivar essa forma de produçáo; e) controle da expedição do selo orgânico, que certifica a qualidade dos produtos orgânicos; f) introdução de um sistema de taxação de pesticidas pelo governo dinamarquês, variando o nível da taxação conforme os impactos dos agrotóxicos na saúde, na natureza e nas águas subterrâneas; g) adoção de um regulamento muito rígido para o uso e comercialização de agrotóxicos, sendo que inúmeros são permitidos no Brasil e que, na Dinamarca, são banidos ${ }^{52}$.

A responsabilização pelas externalidades negativas e a taxação do usuário/poluidor-pagador, mediante instrumentos econômicos, também foram medidas adotadas em outros países como Canadá, Holanda, Noruega, Suécia. Espera-se que esses exemplos sejam replicados no Brasil, em observância do dever de produzir alimentos seguros, por meio da agroecologia, que consiste em "uma tecnologia capaz de confrontar o agronegócio, em qualquer escala" 53 e que resgata os saberes tradicionais e incorpora os progressos científicos e tecnológicos em harmonia com o meio ambiente.

\section{CONSIDERAÇÓES FINAIS}

No julgamento da ADI 5553, o STF lidará com o desafio da sustentabilidade ecológica e suas implicaçóes para a ideia de justiça, haja vista que está em jogo o direito das pessoas em estarem livres de agrotóxicos e de processos de produçáo que coloquem em risco o meio ambiente, a saúde da população e a soberania alimentar do país.

Diversos fundamentos constitucionais e previstos no direito internacional são violados com a concessão das desoneraçóes tributárias a agrotóxicos, por prazo indeterminado. Bilhóes de reais deixam de ingressar aos cofres públicos para estimular um modo de produção insustentável a médio e longo prazo. Somam-se à renúncia fiscal as externalidades negativas que repercutem nos direitos fundamentais à saúde, à alimentação adequada e ao meio ambiente ecologicamente equilibrado.

Cumpre realçar que a $\mathrm{CRFB} / 88$, a jurisprudência e a doutrina contemplam o princípio de vedação do retrocesso ambiental e a proibição de sobreposição de interesses econômicos sobre o plexo de direitos coletivos lato sensu mencionados.

De uma só vez são violados, ainda, os princípios da seletividade, da prevenção, da precaução, do poluidor-pagador e o princípio da sustentabilidade, o qual se projeta como um dos pilares da sociedade moderna, tal como a justiça, a igualdade e a liberdade, conforme

52 NIELSEN, L. Diálogo sobre a concessão de isençóes tributárias a agrotóxicos: audiência pública sobre a Ação Direta de Inconstitucionalidade no 5553, 2019.

53 MACHADO, L. C. P.; MACHADO FILHO, L. C. P. Op. Cit.,. p. 36. 
defendido por Klaus Bosselmann, não podendo a qualificação de sustentável ser considerada isoladamente em relação ao desenvolvimento.

Concebe-se a justiça ecológica como uma integração entre a justiça intrageracional, a justiça intergeracional e a justiça interespécies, devendo ser resgatadas as virtudes enumeradas por Aristóteles para garantia do senso de interdependência e interconectividade que deve reger a governança e que se projeta como chave para as decisóes futuras.

Padecem de inconstitucionalidade material as Cláusulas Primeira (em parte) e Terceira do Convênio ICMS 100/97 do Conselho Nacional de Política Fazendária (CONFAZ), e do Decreto 7.660, de 23 de dezembro de 2011, relativo à isenção total de IPI aos agrotóxicos, os quais não são produtos essenciais e, tal como ocorre com cigarros e bebidas alcoólicas, devem receber tributação máxima e os recursos provenientes da arrecadação serem destinados ao SUS e à políticas públicas de fortalecimento da agroecologia, haja vista o desalinhamento dessas políticas já detectado pelo TCU.

A exigibilidade judicial como a possibilidade de exigir a realização de direitos junto ao Poder Judiciário, sobretudo ao guardião das normas constitucionais, traz à tona o desafio do STF de integrar a sustentabilidade como princípio fundamental e as implicaçóes futuras do julgamento da ADI 5553, tanto para os brasileiros quanto para os ecossistemas, ambos dependentes da conexão essencial entre o pensar, o querer e o agir.

A sociedade civil emerge como um catalisador da agenda da sustentabilidade e, em atuação coordenada com as instituiçôes, organizaçóes e os movimentos sociais, é possível combater o esvaziamento das políticas públicas. Insta destacar a contribuiçáo dos Fóruns Estaduais e do Distrito Federal de Combate aos Impactos dos Agrotóxicos, bem como da Campanha Permanente Contra os Agrotóxicos e Pela Vida, que é uma articulação composta por mais de 100 organizaçóes no Brasil, destinada a denunciar o uso de agrotóxicos no país e promover a agroecologia como modelo de produção em defesa da saúde e da vida.

As questóes relacionadas com o direito à alimentaçáo, à saúde e ao meio ambiente ecologicamente equilibrado precisam ser pautadas transversalmente na agenda de diferentes setores de governo e da sociedade e devem ser abordadas de forma integrada, de modo a potencializar e qualificar o que vem sendo feito.

A CRFB/88 consagra a natureza institucional brasileira de Estado Democrático de Direito logo em seu artigo $1^{\circ}$. Independente do grau de efetivação de tal preceito na prática das relações, a democracia está estampada na intenção constitucional e parametriza os traços de nosso sistema jurídico. $\mathrm{O}$ viés de transformação social proposto pela Constituição harmoniza com este objetivo democrático, bem como com a adjetivação "Estado Democrático de Direito Ambiental".

A garantia dos direitos albergados na CRFB/88 e o usufruto pelo povo dos bens jurídicos mediante a devida proteçáo pelo Estado são pressupostos para a construção de uma sociedade mais justa, em que resguardados os objetivos fundamentais da República Federativa do Brasil, como a erradicação da pobreza e redução das desigualdades sociais e regionais e, ainda, os Objetivos do Milênio, propostos pela ONU, para afirmação da cidadania e garantia do mínimo existencial. 
Depreende-se haver a harmonia desses preceitos com os objetivos da Defensoria Pública da União: primazia da dignidade da pessoa humana, redução das desigualdades sociais, prevalência e efetividade dos direitos humanos de necessitados e pessoas em situação de vulnerabilidade. Nesse sentido, é cabível o pedido de habilitação da Defensoria Pública da União na qualidade de amicus curiae ou a intervenção como custos vulnerabilis na ADI 5553.

A Defensoria Pública da União, instituição destinada a prestar assistência jurídica gratuita e que tem como função precípua a defesa de grupos sociais específicos que mereçam especial proteção, deve dar atenção prioritária à proteção do direito social à alimentação adequada, do direito difuso ao meio ambiente ecologicamente equilibrado, à segurança alimentar e à saúde, prevenindo retrocessos e promovendo o avanço na proteção de bens jurídicos de valor inestimável.

\section{REFERÊNCIAS}

AMARO, L. Direito tributário brasileiro. 17. ed. São Paulo: Saraiva, 2011.

ARAGÃO, A. O princípio do poluidor pagador: pedra angular da política comunitária do ambiente. São Paulo: Instituto O Direito por um Planeta Verde, 2014. v. 1. Disponível em: $<$ https:/www.uc.pt/fduc/ij/publicacoes/pdfs/Poluidor_Pagador_Alexandra_Aragao_Planete_ Verde.pdf>. Acesso em: 18 jun. 2020.

ARANHA, A. Multinacional é condenada por morte de trabalhador contaminado por agrotóxicos. Repórter Brasil, dez. 2018. Disponível em: <https://reporterbrasil.org.br/2018/12/ multinacional-e-condenada-por-morte-de-trabalhador-contaminado-por-agrotoxicos-emfazenda-de-abacaxis/>. Acesso em: 22 nov. 2019.

AUGUSTO, L. G. S. et al. (Org.). Dossiê Abrasco: um alerta sobre os impactos dos agrotóxicos na saúde. São Paulo: Expressão Popular, 2015.

BENJAMIN, A. H. V. e. Meio ambiente e constituição: uma primeira abordagem. In: CONGRESSO INTERNACIONAL DE DIREITO AMBIENTAL, São Paulo. 2002. Anais.... Sáo Paulo: IMESP, 2002, v. 6, p. 89-101.

BOMBARDI, L. M. Geografia do uso de agrotóxicos no Brasil e conexóes com a Uniáo Europeia. São Paulo: FFLCH-USP, 2017.

BOSSELMANN, K. The principle of sustainability: transforming law and governance. Farnham: Ashgate, 2008.

BRASIL. Conselho Nacional de Segurança Alimentar e Nutricional da Presidência da República. E.M. no 003-2013, de $1^{\circ}$ de julho de 2013. Brasília, DF: Consea, 2013. Disponível em: <http://www4.planalto.gov.br/consea/eventos/plenarias/exposicoes-de-motivos/2013/e-mno-003-2013/view>. Acesso em: 15 jun. 2020.

. Departamento de Vigilância em Saúde Ambiental e Saúde do trabalhador do Ministério da Saúde do Brasil. Nota informativa contendo esclarecimentos sobre pulverizaçáo aérea e o controle de endemias. Brasília, DF: Ministério da Saúde, 2016. Disponível em: $<$ http://www.saude.gov.br/images/pdf/2016/marco/30/Esclarecimentos-sobre-pulveriza----o-a-rea-e-o-controle-de-endemias.pdf>. Acesso em: 18 jun 2020. 
- Instituto Brasileiro do Meio Ambiente e dos Recursos Naturais Renováveis. Relatórios de comercializaçáo de agrotóxicos. Brasília, DF: Ibama, 2015. Disponível em: <http://www.ibama.gov.br/phocadownload/qualidadeambiental/relatorios/2014/grafico_ historico_comercializacao_2000_2014.pdf>. Acesso em: 15 jun. 2020.

Procuradoria-Geral da República. Parecer na ADI 5553. Brasília, DF: PGR, 2017. Disponível em: <https://portal.stf.jus.br/processos/downloadPeca.asp?id=313047027\&ext=.pdf>. Acesso em: 26 jun. 2020.

Supremo Tribunal Federal. Tribunal Pleno. ADI 5592. Relatora: Ministra Cármen Lúcia. Relator para Acórdão: Ministro Edson Fachin. Brasília, DF, de 11 de setembro de 2019. Brasília, DF: STF, 2019. Disponível em: <http://redir.stf.jus.br/paginadorpub/paginador. jsp?docTP=TP\&docID=752184165>. Acesso em: 29 jun 2020.

. Tribunal de Contas da União. Acórdáo 709/2018 Plenário. Relator Augusto Nardes. Processo 029.427/2017-7. Brasília, DF: TCU, 2018. Disponível em: <https://pesquisa.apps.tcu. gov.br/\#/documento/acordao-completo/*/NUMACORDAO\%253A709/DTRELEVANCIA\% $2520 \mathrm{desc} \% 252 \mathrm{C} \% 2520$ NUMACORDAOINT\%2520desc $/ 6 / \% 2520$ ?uuid=01212240-c2d611 ea-8a94-b376c393e359>. Acesso em: 28 jun. 2020.

CANOTILHO, J. J. G. O princípio da sustentabilidade como princípio estruturante do direito constitucional. Tékhne: Revista de Estudos Politécnicos, Barcelos, v. 8, n. 13, p. 7-18, 2010.

CARRAZA. R. A. Curso de direito constitucional tributário. 20. ed. São Paulo: Malheiros, 2004.

CARSON, R. Primavera silenciosa. São Paulo: Gaia, 2010.

CARVALHO, D. W. de. Desastres ambientais e sua regulação jurídica: deveres de prevenção, respostas e compensação ambiental. São Paulo: Revista dos Tribunais, 2015.

CARVALHO, P. de B. Curso de direito tributário. 23. ed. São Paulo: Saraiva, 2011.

COSTA, R. H. Apontamentos sobre a tributação ambiental no Brasil. In: TORRES, H. T. (Org.). Direito tributário ambiental. Sáo Paulo: Malheiros, 2005, p. 312-332.

CUNHA, L. N. da.; PORTO, M. F. de S.; SOARES, W. L. Uma política de incentivo fiscal a agrotóxicos no Brasil é injustificável e insustentável: relatório produzido pela Abrasco através do GT Saúde e Ambiente, com o apoio do Instituto Ibirapitanga. Brasília, DF: Arasco, 2020. Disponível em: <https://www.abrasco.org.br/site/wp-content/uploads/2020/02/RelatorioAbrasco-Desoneracao-Fiscal-Agrotoxicos-17.02.2020.pdf.> Acesso em: 10 jun. 2020.

HOLMES, S.; SUNSTEIN, C. R. The cost of rights: why liberty depends on taxes. New York: W.W. Norron \& Company, 1999.

LOUREIRO, J. C. S. G. Constituiçáo e biomedicina: contribuição para uma teoria dos deveres bioconstitucionais na esfera da genética humana. 2003. Tese (Doutorado em Ciências JurídicoPolíticas) - Universidade de Coimbra, Coimbra, 2003.

LUQUESI, T.; TÚLIO, S. Pesquisa da UFG, em parceria com uma universidade da Louisiana, nos EUA, concluiu que agrotóxico penetra além da casca da maçã. G1 Goiás, Goiânia, 16 jun. 2016. Disponível em: <https:/g1.globo.com/go/goias/noticia/2019/06/16/pesquisa-da-ufg-concluiuque-agrotoxico-penetra-alem-da-casca-da-maca.ghtml>. Acesso em: 23 nov. 2020.

MACHADO, H. de B. Curso de direito tributário. São Paulo: Malheiros, 2009. 
MACHADO, L. C. P.; MACHADO FILHO, L. C. P. A dialética da agroecologia: contribuição para um mundo com alimentos sem veneno. São Paulo: Expressão Popular, 2014.

MACHADO, P. A. L. Direito ambiental brasileiro. 22. ed. São Paulo: Malheiros, 2014.

MILARÉ, É. Direito do ambiente. 10. ed. São Paulo: Revista dos Tribunais, 2015.

NIELSEN, L. Diálogo sobre a concessáo de isençóes tributárias a agrotóxicos: audiência pública sobre a Ação Direta de Inconstitucionalidade no 5553. Brasília, DF: MPF, 2019. Disponível em: <http://www.mpf.mp.br/atuacao-tematica/ccr4/dados-da-atuacao/eventos/audiencia-publica/ audiencia-publica-isencao-fiscal-de-agrotoxicos/Dinamarca.pdf/view>. Acesso em: 3 jul. 2020.

PRIMAVESI, A. Manejo ecológico del suelo. Buenos Aires: El Ateneo, 1982.

RIGOTTO, R. M. Agrotóxicos, trabalho e saúde: vulnerabilidade e resistência no contexto da modernização agrícola no Baixo Jaguaribe/CE. Fortaleza: UFC; Expressão Popular, 2011.

SCOFIELD, A. M. Organic farming: the origin of the name. Biological Agriculture and Horticulture, London, v. 4, p. 1-5, 1986.

SILVA, J. A. da. Direito ambiental constitucional. 8. ed. São Paulo: Malheiros, 2010.

SOARES. W. L. Uso dos agrotóxicos e seus impactos à saúde e ao ambiente: uma avaliação integrada entre a economia, a saúde pública, a ecologia e a agricultura. 2009. Tese (Doutorado em Saúde Pública e Meio Ambiente) - Escola Nacional de Saúde Pública Sergio Arouca, Fundação Osvaldo Cruz, Rio de Janeiro, 2009. p. 63. Disponível em: <https://www.arca.fiocruz.br/bitstream/ icict/2589/1/ve_Wagner_Soares_ENSP_2010.pdf>. Acesso em: 15 jun 2020.

STEINER, R. Agriculture course: the birth of the biodynamic method. Rudolf Steiner Archive \& e.Lib, [S.1.], 26 jun. 2007. Disponível em: <https://wn.rsarchive.org/Lectures/GA327/English/ BDA1958/Ag1958_preface.html>. Acesso em: 27 nov. 2020.

TORRES, H. T. Descompasso entre as políticas ambiental e tributária. São Paulo: Consultor Tributário, 2012. Disponível em: <https://www.conjur.com.br/2012-jun-20/consultor-tributariodescompasso-entre-politicas-ambiental-tributaria>. Acesso em: 10 jul. 2020.

VANDERLEI, M. R. Efeitos dos agrotóxicos Kraft ${ }^{\circledR}$ 36EC e Score ${ }^{\circledR} 250$ EC (e seus princípios ativos) em ecossistemas aquáticos: análises comparativas e ecossistêmicas. 2015. Dissertação (Mestrado em Engenharia Ambiental) - Universidade de São Paulo, São Carlos, 2015. Disponível em: $\quad$ https://www.teses.usp.br/teses/disponiveis/18/18139/tde-30052016-102950/publico/ DissertacaoMarinaReghiniVanderlei.pdf>. Acesso em: 24 jun. 2020. 